\title{
Crisscross anchor-stents to prevent metal stent migration during endoscopic ultrasound-guided hepaticogastrostomy
}

Endoscopic ultrasound-guided hepaticogastrostomy (EUS-HGS) has become increasingly utilized to palliate malignant biliary obstruction in patients with inaccessible papillae as a result of duodenal tumor invasion [1,2]. Although a covered self-expandable metal stent (SEMS) is preferred to a plastic stent in EUS-HGS because of its lower risk of bile leakage [3], SEMS migration can be a fatal complication [4]. Herein, we present a case in which a SEMS at risk of proximal migration was successfully managed by adding plastic stents to serve as an anchor.

An 82-year-old man, who had undergone transpapillary stenting using a covered SEMS for distal bile duct cancer, presented with duodenal obstruction. The biliary SEMS was removed endoscopically, followed by duodenal SEMS placement, and EUS-HGS was performed in segment 3 using a covered SEMS (modified-GIOBOR, width $10 \mathrm{~mm}$, length $10 \mathrm{~cm}, 1-\mathrm{cm}$ uncovered portion at the proximal end; TaeWoong Medical Inc., Gimpo, Korea). The following day, percutaneous transhepatic biliary drainage was performed for cholangitis in segment 2. During this procedure, there was proximal dislocation of the SEMS as a result of interference between the percutaneous transhepatic biliary drainage catheter and the SEMS. A therapeutic duodenoscope (JF-260V, Olympus, Tokyo, Japan) was inserted immediately, and the distal SEMS end was barely observed ( Fig. 1 ). The SEMS was moved $2 \mathrm{~cm}$ into the stomach by grasping its distal end using biopsy forceps. Subsequently, we punctured the covered mesh wall of the SEMS using an endoscopic retrograde cholangiopancreatography (ERCP) cannula and a 0.035-inch guidewire ( $\bullet$ Fig.2), and placed a 5-Fr plastic stent (Geenen, Cook Endoscopy, Winston-Salem, North Carolina, USA). Another plastic stent was placed similarly in a crisscross manner ( $\bullet$ Fig.3). The patient did not develop any further complications, including cholangitis or SEMS migration. The management of SEMS migration in EUS-HGS is technically demanding and potentially requires surgical intervention [5]. Crisscrossing anchor stents can be used as a salvage technique to prevent this complication.
Endoscopy_UCTN_Code_TTT_1AS_2AC

Competing interests: None

\section{Yusuke Shima ${ }^{1,2}$, Hiroyuki Isayama ${ }^{1,2}$, Yukiko Ito ${ }^{1}$, Tsuyoshi Hamada², Yousuke Nakai ${ }^{2}$, Takeshi Tsujino ${ }^{1}$, Ryo Nakata', Kazuhiko Koike ${ }^{2}$}

${ }^{1}$ Department of Gastroenterology, Japanese Red Cross Medical Center, Tokyo, Japan

2 Department of Gastroenterology, Graduate School of Medicine,

The University of Tokyo, Tokyo, Japan

\section{References}

1 Park do H, Koo JE, Oh J et al. EUS-guided biliary drainage with one-step placement of a fully covered metal stent for malignant biliary obstruction: a prospective feasibility study. Am J Gastroenterol 2009; 104: $2168-2174$

2 Hamada T, Isayama $\mathrm{H}$, Nakai $Y$ et al. Transmural biliary drainage can be an alternative to transpapillary drainage in patients with an indwelling duodenal stent. Dig Dis Sci 2014, DOI: $10.1007 /$ s10620-014-3062-1

3 Kawakubo K, Isayama $\mathrm{H}$, Kato $\mathrm{H}$ et al. Multicenter retrospective study of endoscopic ultrasound-guided biliary drainage for malignant biliary obstruction in Japan. J Hepatobiliary Pancreat Sci 2014; 21: 328 - 334

$4 \mathrm{Kim} \mathrm{TH}$, Kim SH, Oh HJ et al. Endoscopic ultrasound-guided biliary drainage with placement of a fully covered metal stent for malignant biliary obstruction. World J Gastroenterol 2012; 18: 2526-2532

5 Hamada T, Nakai Y, Isayama $\mathrm{H}$ et al. Tandem stent placement as a rescue for stent misplacement in endoscopic ultrasonographyguided hepaticogastrostomy. Dig Endosc 2013; 25: 340-341

\section{Bibliography}

DOI http://dx.doi.org/

10.1055/s-0034-1377945

Endoscopy 2014; 46: E563

(c) Georg Thieme Verlag KG

Stuttgart · New York

ISSN 0013-726X

\section{Corresponding author}

\section{Hiroyuki Isayama, MD, PhD}

Department of Gastroenterology

Graduate School of Medicine

The University of Tokyo

7-3-1 Hongo, Bunkyo-ku

Tokyo 113-8655, Japan

Fax: +81-3-38140021

isayama-tky@umin.ac.jp

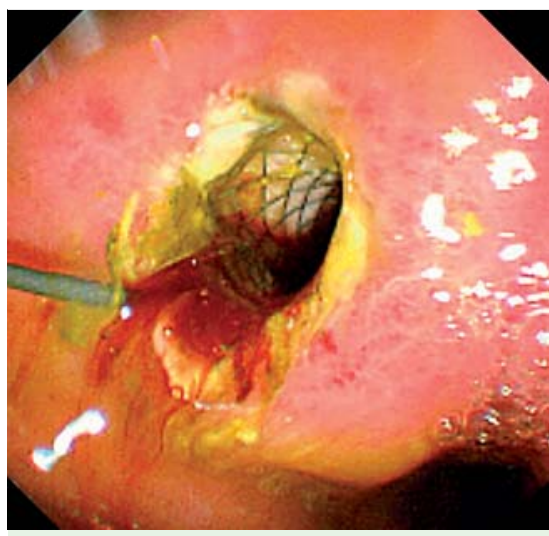

Fig. 1 A covered self-expandable metal stent (SEMS) used for endoscopic ultrasoundguided hepaticogastrostomy (EUS-HGS) had nearly migrated into the peritoneal cavity of an 82-year-old man as a result of interference between the percutaneous transhepatic biliary drainage catheter and the SEMS. The distal end of the stent could barely be seen.

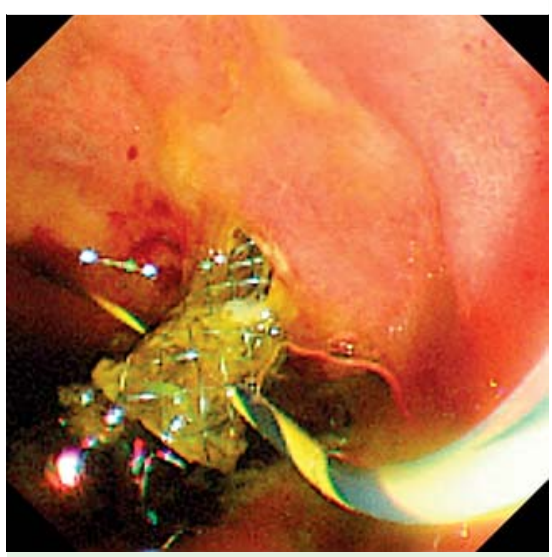

Fig. 2 An endoscopic retrograde cholangiopancreatography (ERCP) cannula was used to puncture the mesh wall of the covered self-expandable metal stent (SEMS). A guidewire was then passed through the mesh wall and the opposite wall of the metal stent.

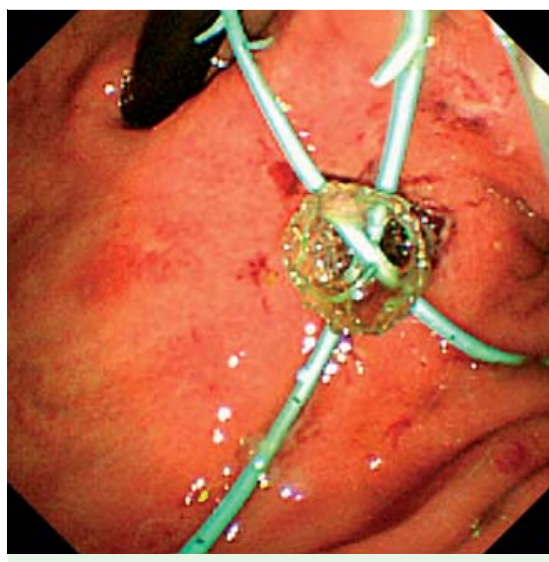

Fig. 3 The crisscrossing anchor stents technique was used to prevent proximal migration of the metal stent. Two crisscrossed 5-Fr plastic stents served as an anchor to prevent stent migration. 